\title{
Validation of the Breast Cancer Screening Beliefs Questionnaire among African Australian women
}

\author{
Cannas Kwok ${ }^{1 *}$, Olayide Ogunsiji ${ }^{1}$ and Chun Fan Lee ${ }^{2}$
}

\begin{abstract}
Background: The Breast Cancer Screening Beliefs Questionnaire (BCSBQ) has been designed as a culturally appropriate instrument for assessing women's beliefs, knowledge and attitudes to breast cancer and breast cancer screening practices. While it has proved to be a reliable instrument when applied to women of Chinese, Arabic and Korean origin living in Australia, its psychometric properties among women from African backgrounds have not been tested. The aim of this study is to examine the psychometric properties of the BCSBQ among African Australian women.

Methods: The BCSBQ was administered to 284 African Australian women who were recruited from a number of African community organizations and churches. Factor analysis was conducted to study the factor structure. Construct validity was examined using Cuzick's non-parametric test while Cronbach alpha was used to assess internal consistency reliability.

Results: Exploratory factor analysis results demonstrated that the African-Australian BCSBQ can be conceptualized as a 4-factor model. The third factor, viz. "barriers to mammography", was split into two separate factors namely, "psychological" and "practical" barriers. The results indicated that the African-Australian BCSBQ had both satisfactory validity and internal consistency. The Cronbach's alpha of the three subscales ranged between 0.84-0.92. The frequency of breast cancer screening practices (breast awareness, clinical breast-examination and mammography) were significantly associated with attitudes towards general health check-ups and perceived barriers to mammographic screening.

Conclusions: Our study provided evidence to support the psychometric properties of the BCSBQ.in African Australian women. The study moreover demonstrated that the use of the instrument can help health professionals to understand the beliefs, knowledge and attitudes to breast cancer among African Australian women and also the factors that impact on their breast cancer screening practices.
\end{abstract}

\section{Background}

While Europe and Asia have traditionally been the largest sources of migration to Australia, there also has been large-scale immigration from Africa over the last two decades. As a result, since 2005 people of African origin have become one of the top ten immigrant populations in Australia [1]. The significant increase of culturally diverse population groups has posed a challenge

\footnotetext{
*Correspondence: c.kwok@westernsydney.edu.au

'School of Nursing and Midwifery, Western Sydney University, Sydney, New South Wales, Australia

Full list of author information is available at the end of the article
}

to health care professionals seeking to promote preventive health measures such as breast cancer screening. The task has been made more difficult by the fact that common preventive measures, particularly mammography, are not well promoted in African countries [2].

Yet breast cancer is a health concern for all women regardless of their ethnic background and in fact is the most common form of cancer among first generation female immigrants living in Australia [3]. Although nearly a quarter of the Australian population are overseas-born [1], the proportion of African Australian women diagnosed with breast cancer is currently unknown. And while the five year survival rates among women diagnosed with breast cancer in Australia increased from $72 \%$ to $89 \%$ between 
1982 and 2014 [4], this promising statistic does not indicate whether the improvement was common to all ethnic or racial groups. In addition, there is a paucity of evidence on the uptake of breast cancer screening, of mortality and of survival rates among African Australian women.

The bulk of studies on the incidence of breast cancer among immigrant African women emanate from the United States of American (USA) and suggest that the incidence of breast cancer in this group is lower than among Caucasian women [5]. However, two statistics have alarming implications: firstly, that breast cancer occurs more commonly among pre-menopausal women and secondly, that their breast cancer is likely to be detected at a more advanced stage, resulting in poor mortality rates $[2,6]$.

Late detection may be due to lack of participation in breast cancer screening measures. To ascertain whether this is the case, there has been considerable research effort mostly in the USA [7-10] but also in other countries such as the United Kingdom, into the breast cancer screening behaviours of immigrant African women. [11, 12]. International studies indicate that as in the case of immigrant women from other minority ethnic groups [13-16] culturally-based beliefs about cancer have an important impact on immigrant African women's cancer screening behaviours $[8,17,18]$. For example, fatalistic attitudes are particularly prominent in African cultures [19]. Studies conducted in the USA $[9,20]$ and the UK [12] demonstrate that fatalism among immigrant African women results from a combination of fear and avoidance. Breast cancer, or any form of cancer for that matter, is seen as an inescapable death sentence and that early detection by means of screening will make no difference to that outcome. Moreover, like Chinese immigrant women $[15,21]$, most women from Africa refuse to think about cancer when they are asymptomatic. In addition it has been suggested in the study conducted by Ndukwe and colleagues [22], that cancer carries a stigma and therefore is a taboo subject or is only discussed in strict confidence [23].

African immigrants may have different model of health care that influences their ideas about illness and health seeking behaviours [10, 17]. Many African seek medical advice only when they are symptomatic. International studies indicate that acceptance of the concept of screening as a secondary preventive measure, which is well established in many Western countries, may be foreign to women from minority cultures. In the absence or signs or symptoms of cancer, immigrant women perceive no need for breast screening measures [10, 24-26].

Studies have also demonstrated that African immigrant women often have little or no knowledge about breast cancer screening measures $[18,27]$. This is not surprising since early detection of breast cancer is not seen as a priority in many African countries where most health outlays are devoted to HIV alleviation [2]. In the only published
Australian study, conducted by Oguniji and colleagues [28], West African immigrant women reported being unaware of breast cancer prior to migrating to Australia.

As in the case of other minority groups, international studies have also identified common barriers to mammographic screening such as lack of transport, lack of English proficiency, the likely costs in the absence of health insurance and fear of cancer diagnosis $[10,13,24,25,29,30]$. To this list must be added ignorance of the existence of screening measures; making it quite likely that many African Australian women may not aware of the national screening program which offers women aged between 50 and 74 free mammograms every two years [31]. However, there is no definite proof of this since studies about breast cancer screening behaviours among African Australian women are scarce to non-existent.

This situation leads us to assert that a culturally sensitive instrument to assess African Australian women's knowledge of and attitudes towards early breast cancer detection measures is essential. The aim of the present study was to assess and report the psychometric properties of the Breast Cancer Screening Beliefs Questionnaire [BCSBQ] among African Australian women. Recently, the BCSBQ has been validated among Arabic [32], Korean [33] and Indian [34] communities. All these studies have demonstrated a high degree of reliability, suggesting that women from minority cultures in Australia share certain cultural beliefs about breast cancer and breast cancer screening. However, to date the extent to which these cultural beliefs concur with the views of African Australian women has been unknown. In this study we demonstrate how the BCSBQ has been used to fill this lacuna.

\section{Methods}

A cross sectional study design was used in this study.

\section{Participants and recruitment}

The participants of this study were African Australian women who met the following criteria: (1) being aged 18 years and over; (2) were resident in Sydney and (3) had no history of breast cancer. Women in the last category were excluded because of the possibility that their cancer diagnosis might have changed their beliefs, knowledge and attitudes toward breast cancer and screening behaviours. The term African Australian women refers to any female of self-reported African descent who has migrated to Australia.

\section{Recruitment and data collection}

Convenience sampling was utilised in recruiting the participants for the study. Leaders of African community women's organisations and associations in Sydney and also African churches were approached to gain access to their 
female members. The second author, who is from African background, provided details of the study to community leaders and explained its aims and procedures to them. While some leaders offered assistance in distributing the questionnaire, some preferred the second author's personal attendance in meetings at which the questionnaires were distributed, completed and collected. Participants also had the option of returning the questionnaire in a stamped, addressed envelope. Other means of gaining participation included personal networking and attendance at African community events and end-of-the-year activities.

Data were collected between October 2013 and December 2014. Prior to data collection, the participants were notified that ethics approval for the study had been obtained. An information sheet containing detailed information was given to the women and a participant's completion of the questionnaire was considered to constitute her written consent.

\section{The BCSBQ instrument}

The BCSBQ, first developed in English, is a 13-item instrument designed to investigate behaviours in terms of three subscales as follows: 1) Attitudes towards general health check-ups, with a subscale of four items designed to determine the participants' attitudes to undergoing such checks in the absence of signs and symptoms of disease; 2) Knowledge and perceptions about breast cancer, with a subscale of four items designed to elicit information on the participants' cultural beliefs regarding breast cancer; 3) Barriers to mammographic screening practices, with a subscale of five items covering what participants perceive as psychological and practical barriers that prevent or at least discourage them from participating in mammographic screening. For the purpose of this paper, the term "The African-Australian BCSBQ" is used.

Figure 1 gives a brief description of each item of the subscales. Participants were asked to rate these items along a five point Likert scale ranging from 'Strongly agree' (score of 1) to 'Strongly disagree' (score of 5). Lower scores in each subscale indicated the less proactive attitudes, less knowledge or greatest barriers to mammography. Unlike the BCSBQs administered earlier to linguistically homogenous groups of Chinese, Korean and Arabic women which were translated into their respective languages, the wide linguistic diversity of African languages meant that the African-Australian BCSBQ had to be administered in English. This was not a great disadvantage because as set out below, most participants claimed to have good English fluency. In order to ensure the clarity, understand ability and readability of the instrument, it was piloted among 15 African Australian women with various demographic backgrounds who unanimously confirmed its comprehensibility.

In addition to the information obtained from the African-Australian BSCBQ, demographic information about age, length of stay in Australia, English language proficiency and highest level of educational attainment was collected. The participants were also asked about the frequency with which they undertook the basic screening practices of breast awareness (knowing the normal look and feel of their breasts, without needing to apply a special technique), clinical breast examination (CBE) and mammography.

\section{Sample size}

We planned to recruit over 200 participants to ensure an adequate sample size required for factor analysis of the 13-item BCSBQ, using the rule of thumb of 10 subjects per item [35]. Approximately 500 African Australian women were invited to participate in the study. The questionnaire was returned by 284 women, giving a response rate of $56.8 \%$. Among the 20 women excluded from the study, 14 had history of breast cancer and six did not complete the questionnaire. The final sample size was thus 264, well within the acceptable sample size for the confirmatory factor analysis (CFA).

\section{Statistical analysis}

The demographic characteristics of the participating women were summarized using descriptive statistics. The originally designed 3-factor structure of the BCSBQ questionnaire was first examined using a CFA of this cohort. The covariance matrix of the 13 items was first computed and then factor-analyzed using maximum likelihood method. Goodness-of-fit of the factor model was assessed by the fit indices with respective common criteria, namely the root mean square error of approximation (RMSEA $\leq$ 0.06), standardized root mean square residual (SRMR $\leq$ $0.08)$, comparative fir index $(\mathrm{CFI} \geq 0.95)$, and non-normed fit index (NNFI $\geq 0.95)$, which addressed the parsimony correction, absolute fit, and comparative or incremental fit, as recommended [36, 37]. When there were doubts about inadequate fit, addition of covariance between items was made based on the largest modification index [38]. If the 3-factor structure could not be confirmed by the above criteria, an exploratory factor analysis (EFA) would be conducted. The number of factors would be determined by the scree plot. Factor loadings after a varimax rotation would be computed.

The subscale scores of the questionnaire were then calculated on the same basis as the original version previously reported by Kwok et al. [39]. The half-rule was applied, i.e., missing values were imputed by the mean of the responses in the same subscale, provided at least half of the items in that subscale were valid. Floor and ceiling effects were examined to determine whether the 5-point Likert scale was sufficient to distinguish the responses at the two extremes clearly. Internal consistency reliability for each subscale was evaluated by the Cronbach's alpha. 


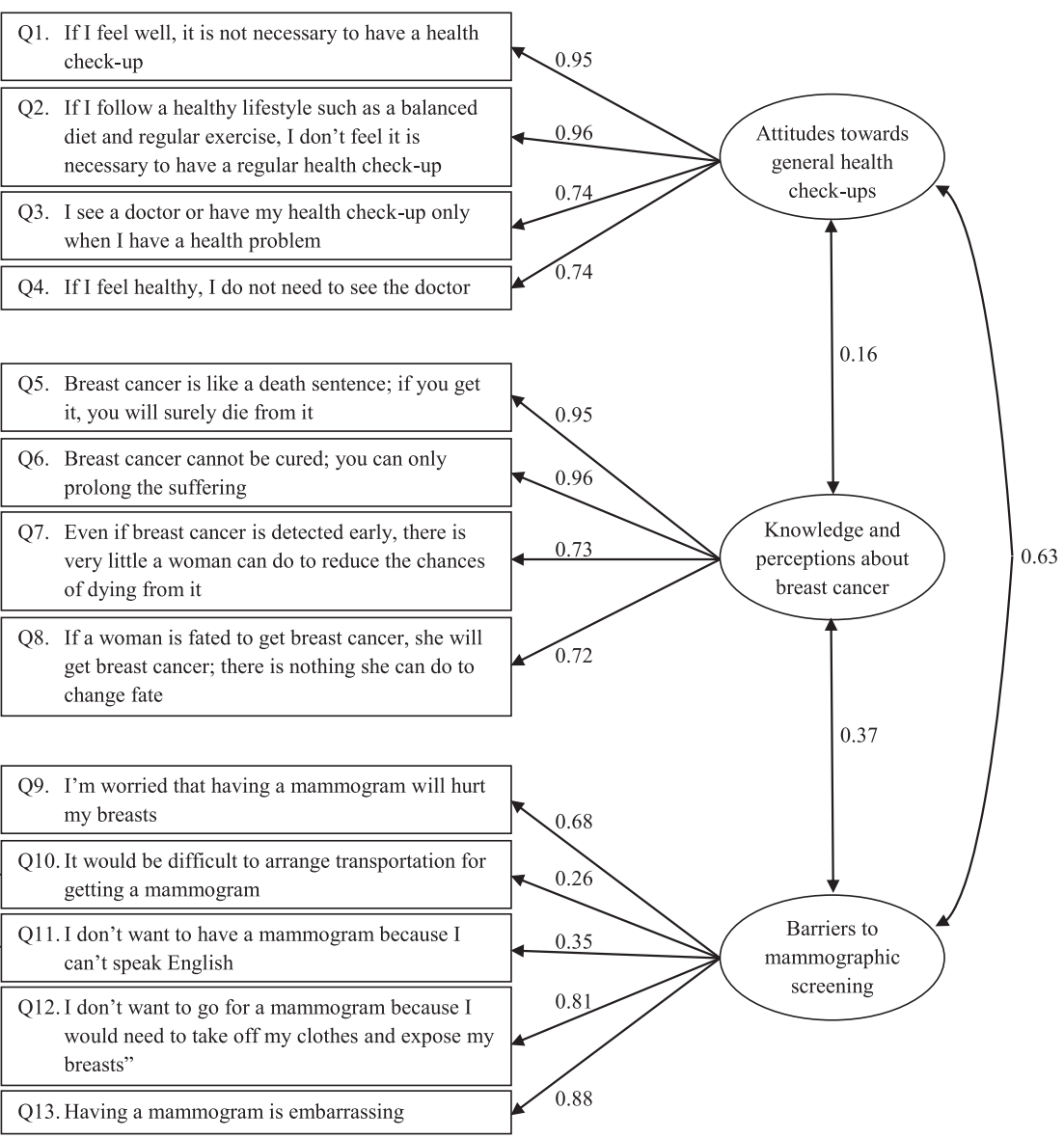

Fig. 1 Path diagram of a confirmatory factor analysis of the African Breast Cancer Screening Beliefs Questionnaire. The values correspond to the standardized estimates

A good Cronbach's alpha should range from 0.7 to 0.9 . A Cronbach's alpha lower than 0.7 may indicate a low degree of homogeneity whereas a value much higher than 0.9 may imply item redundancy [35].

Construct validity was also examined by testing three hypotheses regarding the association between the subscale scores and the frequency of screening practices and/or education level: (1) those who performed breast awareness exercises and/or presented themselves for $\mathrm{CBE}$ and mammograms more frequently, were likely to have a more proactive attitude towards breast cancer screening as reflected by a higher Attitude subscale score; (2) those who achieved higher education levels would be more knowledgeable about breast cancer screening and thus record higher Knowledge subscale scores; (3) those who had more frequent screening practices were associated with fewer barriers to breast cancer screening, which resulted in a higher Barriers subscale score. Because of the ordinal-type nature of the frequency of screening practices and education level, the trend was tested by a Cuzick's non-parametric test [40]. All statistical analyses were performed using SAS version 9.3.

\section{Ethical issues}

The research project was approved by the Human Ethics Committee of Western Sydney University number H9759.

\section{Results}

The demographic characteristics of the 264 participants who completed the questionnaire are summarized in Table 1 . Their ages ranged from 18 to 69 , with a mean (standard deviation) of 49.5 (10.4) years. They had lived in Australia for a mean of 8.7 (4.9) years. Most were married $(66.2 \%)$, had tertiary or higher education qualifications (58.3\%), spoke English at home (74.6\%) and rated their English level as good or very good (86.7 \%).

The CFA of the hypothesized 3-factor structure of the African-Australian BCSBQ resulted in a chi-square statistic $=680.9$ (degrees of freedom $=62, p$-value $<0.001$ ), RMSEA $=0.19$ (95\% confidence interval $(\mathrm{CI})=0.18$ to $0.21), \operatorname{SRMR}=0.15, \mathrm{CFI}=0.78$ and $\mathrm{NNFI}=0.72$. After examining the modification index, a covariance between Q10 and Q11 was added to the factor model and the fit statistics improved but still did not satisfy the pre-specified 
Table 1 Demographic characteristics of the 264 participants

\begin{tabular}{|c|c|c|}
\hline Characteristic & $N$ & $(\%)$ \\
\hline \multicolumn{3}{|c|}{ Age (year) (Mean: 49.5, SD: 10.4, missing: $N=7$ ) } \\
\hline$>20$ & 1 & $(0.4)$ \\
\hline $20-29$ & 10 & $(3.9)$ \\
\hline $30-39$ & 32 & $(12.5)$ \\
\hline $40-49$ & 77 & $(30.0)$ \\
\hline $50-59$ & 92 & $(35.8)$ \\
\hline $60-69$ & 45 & $(17.5)$ \\
\hline \multicolumn{3}{|l|}{ Country of birth } \\
\hline East Africa & 17 & $(6.4)$ \\
\hline West Africa & 95 & $(36.0)$ \\
\hline North Africa & 88 & (33.3) \\
\hline South Africa & 64 & $(24.2)$ \\
\hline \multicolumn{3}{|l|}{ Language spoken at home } \\
\hline African & 18 & $(6.8)$ \\
\hline Dinka & 40 & $(15.2)$ \\
\hline English & 197 & $(74.6)$ \\
\hline Others & 9 & $(3.4)$ \\
\hline \multicolumn{3}{|l|}{ Length of stay in Australia (year) } \\
\hline \multicolumn{3}{|l|}{ (Mean: 8.7, SD: 4.9, missing: $N=12$ ) } \\
\hline $0-5$ & 70 & $(27.8)$ \\
\hline $6-10$ & 111 & $(44.0)$ \\
\hline $11-15$ & 52 & $(20.6)$ \\
\hline $16-20$ & 12 & $(4.8)$ \\
\hline $21-25$ & 6 & $(2.4)$ \\
\hline 26 or above & 1 & $(0.4)$ \\
\hline \multicolumn{3}{|l|}{ Marital status (missing: $N=1$ ) } \\
\hline Single & 19 & $(7.2)$ \\
\hline Married/defacto (living together) & 174 & $(66.2)$ \\
\hline Divorced/separated & 60 & $(22.8)$ \\
\hline Widowed & 10 & (3.8) \\
\hline \multicolumn{3}{|l|}{ Education level } \\
\hline Primary school & 20 & $(7.6)$ \\
\hline Secondary school & 47 & $(17.8)$ \\
\hline TAFE/college & 43 & $(16.3)$ \\
\hline Tertiary or above & 154 & $(58.3)$ \\
\hline \multicolumn{3}{|c|}{ Current employment status (missing: $N=1$ ) } \\
\hline Employed, full time & 125 & $(47.5)$ \\
\hline Employed, part time & 94 & $(35.7)$ \\
\hline Unemployed & 38 & $(14.4)$ \\
\hline Retired & 6 & $(2.3)$ \\
\hline \multicolumn{3}{|l|}{ Self-rated English level } \\
\hline Little & 14 & (5.3) \\
\hline Average & 21 & $(8.0)$ \\
\hline Good & 79 & $(29.9)$ \\
\hline Very good & 150 & $(56.8)$ \\
\hline
\end{tabular}

criteria: chi-square statistic $=422.1$ (degrees of freedom $=$ 61, $p$-value $<0.001), \quad$ RMSEA $=0.15(95 \% \mathrm{CI}=0.14$ to $0.17), \mathrm{SRMR}=0.13, \mathrm{CFI}=0.87$ and $\mathrm{NNFI}=0.83$. The final CFA model is shown in Figure 1.

Since the hypothesized 3-factor structure could not be confirmed through the CFA, an EFA was performed as planned. The eigenvalues for the first five factors were 6.04, 2.21. 1.31, 1.03 and 0.56. Having examined the scree plot, a 4-factor model was identified, the varimaxrotated loadings of the four factors being presented in Table 2. These factors together explained $81.5 \%$ of the total variance. Items having a loading with magnitude $\geq$ 0.4 within a particular factor were considered to be its major component and are highlighted. All items on the Attitude and Knowledge subscale were loaded more heavily on the first and second factors respectively, while the items on the Barriers subscale loaded the third and fourth factors. As noted earlier, the third factor consisted of three items designed to establish psychological barriers to mammographic screening. These were: "I'm worried that having a mammogram will hurt my breasts (Q9)," "I don't want to go for a mammogram because I would need to take off my clothes and expose my breasts (Q12)" and "Having a mammogram is embarrassing (Q13)". The fourth factor consisted of two items related to practical barriers: "It would be difficult to arrange transportation for getting a mammogram (Q10)" and "I don't want to have a mammogram because I can't speak English (Q11)". Therefore, apart from examining the main Barrier scale, we split the remaining validation into two "daughter" subscales, namely Psychological and Practical barriers.

Table 3 presents the distributions of the score of the subscales. Five women did not answer all items which meant that the half-rule could not be applied to compute the score of the Barriers subscale and its two daughter subscales. The subscales under Attitude and Knowledge had a range from 0 to 100, while the Barrier subscale had a minimum score of 5 . There were very mild ( $\leq 3 \%$ ) floor and ceiling effects for the three original as well as the Psychological barriers subscale, but $15.5 \%$ of the women attained the maximum score of 100 for the Practical barrier subscale. The Cronbach's alpha of the Attitude, Knowledge and Barriers subscales were $0.92,0.91$ and 0.77 respectively. However, after splitting the Barriers subscale into two, the Cronbach's alphas improved to 0.84 for Psychological barriers and 0.86 for Practical barriers.

The mean scores of the three original subscales and two daughter subscales, stratified by the participants' education levels and frequency of screening practices, are shown in Table 4. Women with higher education levels obtained significantly higher scores in all subscales (all $p$-values $<0.01)$. The Attitude subscale score was 
Table 2 Rotated factor loadings of the exploratory factor analysis of the African Breast Cancer Screening Beliefs Questionnaire

\begin{tabular}{|c|c|c|c|c|}
\hline \multirow[b]{2}{*}{ Items } & \multicolumn{4}{|c|}{ Factor loadings } \\
\hline & Factor 1 & Factor 2 & Factor 3 & Factor 4 \\
\hline \multicolumn{5}{|c|}{ Attitudes towards general health check-ups } \\
\hline Q1 & 0.84 & 0.31 & 0.00 & 0.15 \\
\hline Q2 & 0.83 & 0.34 & 0.01 & 0.17 \\
\hline Q3 & 0.83 & 0.26 & 0.03 & 0.15 \\
\hline Q4 & 0.82 & 0.30 & 0.09 & 0.11 \\
\hline \multicolumn{5}{|c|}{ Knowledge and perceptions about breast cancer } \\
\hline Q5 & 0.29 & 0.82 & 0.11 & 0.25 \\
\hline Q6 & 0.28 & 0.84 & 0.16 & 0.21 \\
\hline Q7 & 0.35 & 0.79 & 0.06 & 0.09 \\
\hline Q8 & 0.36 & 0.79 & 0.13 & 0.00 \\
\hline \multicolumn{5}{|c|}{ Barriers to mammographic screening } \\
\hline Q9 & 0.13 & -0.08 & 0.85 & 0.08 \\
\hline Q10 & 0.21 & 0.13 & 0.11 & 0.91 \\
\hline Q11 & 0.17 & 0.19 & 0.18 & 0.89 \\
\hline Q12 & -0.06 & 0.18 & 0.85 & 0.16 \\
\hline Q13 & 0.03 & 0.24 & 0.86 & 0.07 \\
\hline
\end{tabular}

significantly higher among those who had more frequent CBEs and mammograms, but marginally insignificantly higher among those who performed more frequent breast awareness exercises ( $p$-value $=0.068$ ). The main Barriers subscale score in contrast, was significantly associated only with the frequency of breast awareness exercises $(p$-value $=0.028)$ and not with frequency of CBEs $(p$-value $=0.104)$ and mammography $(p$-value $=0.451)$. However, after splitting this factor into two daughter subscales, the Practical barrier score showed itself to be significantly associated with all three screening practices (all $p$-values $<0.05)$.

\section{Discussion}

Increasing cancer screening rates among minority populations is vital because early detection is central to reducing morbidity and mortality. This fact lends particular importance to our BCSBQ-based study because it constitutes the first step towards investigating breast cancer screening behaviour and practices among the fastgrowing population of African immigrants to Australia.
In contrast to the BCSBQ studies conducted among Korean, Indian and Arabic immigrant populations in which the results supported the original 3-factor model, the EFA results of the present study demonstrated that the African-Australian BCSBQ could be conceptualized as a 4-factor model. The third subscale, viz, Barriers to mammography, needed to be split into two factors namely Psychological and Practical barriers. The three items on the Psychological (Q9, Q12, Q13) subscale proved to be of little help in evaluating the participants' thinking on this issue and in fact masked the effect of the two items on the Practical barriers (Q10, Q11) subscale. This became clear after the three Psychological items were effectively removed from the main Barriers factor which had revealed that the Cronbach's alpha improved and the three hypothesis tests became (more) significant. Practical barriers such as transportation and English proficiency, had a greater impact on African Australian women's screening behaviours than the Psychological barriers set out above. This finding is in agreement with those of overseas studies conducted

Table 3 Distribution of the subscale scores of the 13-item African Breast Cancer Screening Beliefs questionnaire and Cronbach's Alpha

\begin{tabular}{llllllll}
\hline Subscale & N & Mean & Standard deviation & Median & \% at floor & \% at ceiling & Cronbach's alpha \\
\hline Attitudes towards general health check-ups & 264 & 41.4 & 25.8 & 25.0 & 3.0 & 2.7 & 0.92 \\
Knowledge and perceptions about breast cancer & 264 & 44.7 & 26.2 & 37.5 & 1.5 & 1.9 & 0.91 \\
Barriers to mammographic screening & 261 & 56.7 & 16.7 & 55.0 & 0 & 1.1 & 0.77 \\
Psychological barriers & 259 & 44.3 & 22.2 & 41.7 & 0.4 & 1.5 & 0.84 \\
Practical barriers & 261 & 74.7 & 17.2 & 75.0 & 0 & 15.5 & 0.86 \\
\hline
\end{tabular}


Table 4 Construct validity of the African Breast Cancer Screening Beliefs Questionnaire

\begin{tabular}{|c|c|c|c|c|c|c|}
\hline & & \multirow{2}{*}{$\begin{array}{l}\text { Attitudes } \\
\text { towards } \\
\text { general } \\
\text { health } \\
\text { check-ups }\end{array}$} & \multirow{2}{*}{$\begin{array}{l}\text { Knowledge } \\
\text { and } \\
\text { perceptions } \\
\text { about } \\
\text { breast } \\
\text { cancer }\end{array}$} & \multicolumn{3}{|c|}{ Barriers to mammographic screening } \\
\hline & & & & Original subscale & Psychological barriers & Practical barriers \\
\hline & $N(\%)$ & Mean (SD) & Mean (SD) & Mean (SD) & Mean (SD) & Mean (SD) \\
\hline \multicolumn{7}{|l|}{ Education level } \\
\hline Primary school & $20(7.6)$ & $24.1(15.9)$ & $25.0(16.8)$ & $40.3(17.1)$ & $33.8(16.3)$ & $50.0(24.7)$ \\
\hline Secondary school & $47(17.8)$ & $26.9(19.3)$ & $26.7(18.6)$ & $51.5(13.4)$ & $39.9(16.1)$ & $68.9(16.5)$ \\
\hline TAFE/college & $43(16.3)$ & $40.1(22.8)$ & $39.8(22.8)$ & $55.1(16.3)$ & $40.4(21.0)$ & $75.6(18.5)$ \\
\hline Tertiary or above & $154(58.3)$ & $48.5(26.5)$ & $54.1(25.6)$ & $60.8(15.9)$ & $48.1(24.0)$ & $79.5(12.0)$ \\
\hline$P$-value for trend & & $<0.001$ & $<0.001$ & $<0.001$ & 0.003 & $<0.001$ \\
\hline \multicolumn{7}{|l|}{ Breast awareness } \\
\hline At least once a month & $23(8.7)$ & $42.7(33.6)$ & $44.3(30.3)$ & $63.5(19.0)$ & $52.2(26.3)$ & $80.4(15.5)$ \\
\hline Once every few months & $92(34.8)$ & $42.7(24.9)$ & $47.2(28.4)$ & $56.2(15.2)$ & $40.5(22.0)$ & $79.1(10.7)$ \\
\hline Once a year & $30(15.2)$ & $53.8(23.6)$ & $57.3(21.3)$ & $61.9(14.1)$ & $50.0(23.3)$ & $79.7(10.5)$ \\
\hline Never & $109(41.3)$ & $35.6(24.0)$ & $38.0(23.2)$ & $53.6(17.6)$ & $43.8(20.3)$ & $67.9(21.5)$ \\
\hline$P$-value for trend & & 0.068 & 0.032 & 0.028 & 0.748 & $<0.001$ \\
\hline \multicolumn{7}{|l|}{ Clinical breast examination } \\
\hline A year or less & $4(1.5)$ & $71.9(24.2)$ & $64.6(12.5)$ & $72.5(19.4)$ & $66.7(28.1)$ & $81.3(16.1)$ \\
\hline More than a year and less than two years & $16(6.1)$ & $35.2(24.2)$ & $52.0(28.6)$ & $61.3(21.2)$ & $47.4(29.0)$ & $82.0(11.2)$ \\
\hline Two to three years & $27(10.2)$ & $52.1(24.4)$ & $53.9(23.8)$ & $61.1(13.7)$ & $50.3(22.5)$ & $77.3(8.5)$ \\
\hline More than three years & $27(10.2)$ & $51.9(25.6)$ & $54.2(26.9)$ & $53.7(14.9)$ & $38.3(19.2)$ & $76.9(17.9)$ \\
\hline Never had one & $190(72.0)$ & $38.3(25.2)$ & $41.0(25.7)$ & $55.7(16.7)$ & $43.6(21.5)$ & $73.3(18.3)$ \\
\hline$P$-value for trend & & 0.020 & 0.004 & 0.104 & 0.203 & 0.045 \\
\hline \multicolumn{7}{|l|}{ Mammogram } \\
\hline Once a year & $10(3.8)$ & $58.8(27.0)$ & $53.1(26.4)$ & $59.0(14.1)$ & $37.5(23.0)$ & $91.3(11.9)$ \\
\hline Once every two years & $113(42.8)$ & $42.1(25.3)$ & $42.2(25.6)$ & $57.4(14.1)$ & $43.6(20.7)$ & $78.1(12.3)$ \\
\hline Once every three years or more & $45(17.0)$ & $46.9(27.2)$ & $52.5(26.8)$ & $53.0(16.1)$ & $38.5(20.4)$ & $74.7(18.9)$ \\
\hline Never had one & $96(36.4)$ & $36.3(24.6)$ & $43.1(26.2)$ & $57.3(19.8)$ & $48.9(24.0)$ & $68.8(19.7)$ \\
\hline$P$-value for trend & & 0.041 & 0.975 & 0.451 & 0.412 & $<0.001$ \\
\hline
\end{tabular}

Abbreviation: $S D$ standard deviation

among African immigrant women [10, 24, 30]. Despite the fact that the majority of this cohort had good or very good English proficiency, the practical barriers subscale does include an item relating to concerns about English. It may be that language concerns occur within the technical and medical context of mammograms, and/or that women of African ancestry find it difficult to discuss their modesty concerns. Our findings may indicate that in the future use of this instrument for African participants, the three main Psychological barrier items can be regarded as a separate factor that is separate from the Practical barrier items. This is in line with a similar modification of the BCSBQ conducted among Hong Kong Chinese in which the two Practical barrier items were not included because they had proved to be irrelevant [41].
Similar to the original and other versions, the internal consistency of the three subscales proved excellent, with Cronbach's alpha ranging from 0.77 to 0.92 , comfortably above the acceptable level of 0.70 recommended by Hair et al. [42]. After splitting the Barrier subscale into two, the Cronbach's alpha improved to 0.86 for Practical barriers. However, one drawback of the division of the main Barrier factor was the inflation in the ceiling effect which increased from $1.1 \%$ in the original to $15.5 \%$ under the new the Practical factor. This was not surprising since one of the two items related to concerns about English and more than half the African Australian women in this cohort had attained tertiary or higher education qualifications, spoke English at home and rated their English level as very good. Although the subscale score could not be distinguished among this proportion of participants, it 
had better reliability and discriminative power than the original main Barrier factor across the whole spectrum as evidenced by the Cronbach's alpha and the three hypothesis tests. This again supported the separation of the main Barrier subscale into two daughter factors.

The African-Australian BCSBQ also demonstrated good construct validity with the associations between the three subscales and the frequency of screening practices. In line with studies focused on Chinese, Arabic, Korean and Indian immigrant women, the Attitudes subscale showed significant associations with both CBE and mammographic screening. Our findings on this score are supported by the claim that immigrant women often have different concepts of preventive care and that having cancer screening while asymptomatic is foreign to their health practices [24, 26, 43, 44]. It is evident that the Practical barrier subscale was more significantly associated with breast cancer screening practices, rather than Psychological barriers. This is consistent with the findings of overseas studies which have demonstrated that transportation and language appear as key barriers to mammographic screening among African immigrant women [10, 29].

Our findings also demonstrate that as in the validation study conducted among Korean Australian women [33], the education level of the African group was significantly associated with the three subscales This may be explained by the fact that greater levels of educational attainment create more positive responses to having health check-ups, improving knowledge about breast cancer and lessening the impact of barriers to mammographic screening. This is evident from our finding that African Australian women with better education levels have better understandings of preventative measures, something which counteracts traditional health beliefs focused on curative aspects. Overseas studies across cultural groups likewise indicate education levels as a predictor of women's screening behaviours $[18,45,46]$.

The limitations of this study should be noted when applying the findings. Firstly, participants were born in African countries but resided in Australia. Therefore, these results may not be generalizable to African women living in their home countries. Secondly the study utilised self-reported measures of breast cancer screening practices that could have been over or under-reported. Further studies with adequate verification of self-reported information built into their design, are warranted.

\section{Conclusion}

The psychometric properties assessment of the AfricanAustralian BCSBQ reported in this paper confirm that the instrument is a valid and reliable tool for assessing breast cancer beliefs and attitudes towards screening practices among African-Australian women.

\section{Competing interest}

The authors declare that they have no competing interests.

\section{Authors' contributions}

CK participated in the study design, conceptual framework, data interpretation, draft the manuscript and proof read the final submission. OO participated in the study design, data collection, data interpretation, draft the manuscript and proof read the final submission. CFL participated in the study design, conceptual framework, data analysis and interpretation, draft the manuscript and proof read the final submission.

\section{Acknowledgement}

The authors would like to thank the African community organizations that offered assistance in the recruitment of the sample of women investigated in this study. We also need to thank the African Australian women who participated.

\section{Author details}

${ }^{1}$ School of Nursing and Midwifery, Western Sydney University, Sydney, New South Wales, Australia. ${ }^{2}$ Department of Biostatistics, Singapore Clinical Research Institute, Singapore, Singapore.

\section{Received: 7 October 2015 Accepted: 27 January 2016}

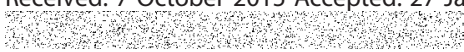

\section{References}

1. Australian Bureau of Statistics. 2015. Yearbook Australia 2012. http://www. abs.gov.au/ausstats/abs@.nsf/mf/1301.0. Accessed April 21, 2015.

2. American Cancer Society. Cancer in Africa. Atlanta: American Cancer Society; 2011

3. Australian Institute of Health and Welfare \& Cancer Australia. Breast cancer in Australian: an overview, Cancer series no. 71. Cat. No. CAN 67. Canberra: AlHW; 2012

4. Australian Institute of Health and Welfare. Cancer in Australia: an overview 2014, Cancer series no 90. Cat. No.CAN 88. Canberra: AlHW; 2014.

5. American Cancer Society. 2015. Cancer facts and figures. http://www.cancer. org/Research/CancerFactsFigures/. Accessed July 21, 2015.

6. Tao L, Gomez SL, Keegan TH, Kurian AW, Clarke CA. Breast cancer mortality in African-American and Non-Hispanic White women by molecular subtype and stage at diagnosis: A population-based study. Cancer Epidemiol Biomarkers Prev. 2015;24:1039-45.

7. Banning M. Perceptions of breast health awareness in Black British women. Eur J Oncol Nurs. 2011;15:173-77.

8. Beckjord E, Klassen A. Cultural values and secondary prevention of breast cancer in African American women. Cancer Control. 2008;15(1):6371.

9. Kaiser K, Cameron K, Curry G, Stolley M. Black women's awareness of breast cancer disparity and perceptions of the causes of disparity. J Community Health. 2013;38:766-72.

10. Wallace R, Torres S, Beltran J, Cohen-Boyar C. Views of mammography screening amnogn U.S. Black and Hispanic immigrant women and their providers. Health Care Women Int. 2014;35:1181-200.

11. Forbes LJ, Atkins L, Thurnham A, Layburn J, Haste F, Ramirez AJ. Breast cancer awareness and barriers to symptomatic presentation among women from different ethnic groups in East London. Br J Cancer. 2011;8(10510):1474-9.

12. Jones CE, Maben J, Jack RH, Davies EA, Forbes LJ, Lucas G, et al. A systematic review of barriers to early presentation and diagnosis with breast cancer among black women. BMJ Open. 2014;12(42):e004076.

13. Ahmad F, Jandu B, Albagli A, Angus JE, Ginsburg O. Exploring ways to overcome barriers to mammography uptake and retention among South Asian immigrant women. Health Soc Care Community. 2013;3(1):88-97.

14. Crawford J, Ahmad F, Beaton D, Bierman AS. Cancer screening behaviours among South Asian immigrants in the UK, US and Canada: a scoping study. Health Soc Care Community. 2016; 24(2):123-53.

15. Kwok C, Sullivan $\mathrm{G}$. The influence of traditional Chinese beliefs on cancer screening behaviours among Chinese-Australian women. J Adv Nurs. 2006;54(6):691-9.

16. Lee EE, Tripp-Reimer T, Miller AM, Sadler GR, Lee SY. Korean American women's beliefs about breast and cervical cancer and associated symbolic meanings. Oncol Nurs Forum. 2007;34:713-20.

17. Russell K, Monahan P, Wagle A, Champion V. Differences in health and cultural beliefs by stage of mammography screening adoption in African American women. Cancer Suppl. 2007;109(2):386-95. 
18. Sadler GR, Ko CM, Cohn JA, White M, Weldon RN, Wu P. Breast cancer knowledge, attitudes, and screening behaviours among African American women: the Black cosmetologists promoting health program. BMC Public Health. 2007;7(57):2458-57.

19. Registe M, Porterfield S. Health beliefs of African American women on breast self-exam. J Nurse Pract. 2012;8(6):446-51.

20. Sheppard VB, Davis K, Boisvert M, Jennings Y, Montalvo B. Do recently diagnosed Black breast cancer patients find questions about cancer fatalism acceptable? A Preliminary report. J Cancer Educ. 2011;26:5-10.

21. Shang C, Beaver K, Campbell M. Social cultural influences on breast cancer views and breast health practices among Chinese women in the United Kingdom. Cancer Nur. 2015;385:343-50.

22. Ndukwe EG, Williams KP, Sheppard V. Knowledge and perspectives of breast and cervical cancer screening among female African immigrants in the Washington D.C. metropolitan area. J Cancer Educ. 2013;284:748-54.

23. Sheppard VB, Christopher J, Nwabukwu I. Breaking the silence barrier: opportunities to address breast cancer in African-born women. J Natl Med Asso. 2010;1026:461-8.

24. Jones CE, Maben J, Lucas G, Davies EA, Jack RH, Ream E. Barriers to early diagnosis of symptomatic breast cancer: a qualitative study of Black African, Black Caribbean and White British women living in the UK. BMJ Open. 2015; 13(53), e006944.

25. Kawar LN. Barriers to breast cancer screening participation among Jordanian and Palestinian American women. Eur J Oncol Nurs. 2013;17:88-94.

26. Kwok C, Tranberg R, Lee F. Breast cancer knowledge, attitudes and screening behaviours among Indian-Australian women. Eur J Oncol Nurs. 12015: In press

27. Muthoni A, Miller A. An exploration of rural and urban Kenyan women's knowledge and attitudes regarding breast cancer and breast cancer early detection measures. Health Care Women Int. 2010;31:801-16.

28. Ogunsiji O, Wilkes L, Peters K, Jackson D. Knowledge, attitudes and usage of cancer screening among West African migrant women. J Clin Nurs. 2013;227(8):1026-33.

29. Kue J, Zukoski A, Keon KL, Thorburn S. Breast and cervical cancer screening: exploring perceptions and barriers with Hmong women and men in Oregon. Ethn Health. 2014;193:311-27.

30. Marlow LA, McGregor LM, Nazroo JY, Wardle J. Facilitators and barriers to helpseeking for breast and cervical cancer symptoms: a qualitative study with an ethnically diverse sample in London. Psychooncology. 2014;237:749-57.

31. BreastScreen Australia. BreastScreen Australia evaluation - Evaluation final report 2012. Australia: BreastScreen; 2014.

32. Kwok C, Endrawes G, Lee F. Breast Cancer Screening Beliefs Questionnaire: Psychometric properties assessment of the Arabic version. Eur J Oncol Nurs. 2015, In press

33. Kwok C, Lee M, Lee F. Validation of the Korean version of the Breast Cancer Screening Beliefs Questionnaire. Cancer Nurs. 2015,In press.

34. Kwok C, Tranberg R, Lee F. Psychometric properties of the Breast Cancer Screening Beliefs Questionnaire among women of Indian ethnicity living in Australia. Cancer Nurs. 2015, In press.

35. Streiner DL, Norman GR, Health measurement scales. A Practical guide to their development and use. 3rd ed. Toronto: Oxford University Press; 2003.

36. Hu LT, Bentler PM. Fit indices in covariance structure modeling: sensitivity to underparameterized model misspecification. Psychol Methods. 1998;3:424-53.

37. Hu LT, Bentler PM. Cutoff criteria for fit indexes in covariance structure analysis: conventional criteria versus new alternatives. Struct Equ Modeling. 1999;6(1):51-5

38. Brown TA. Confirmatory factor analysis for applied research. New York Guilford Press; 2006

39. Kwok C, Fethney J, White K. Chinese Breast Cancer Screening Beliefs Questionnaire: development and psychometric testing with ChineseAustralian women. J Adv Nurs. 2010;66:191-200.

40. Cuzick JA. Wilcoxon-type test for trend. Stat Med. 1985;4:87-90.

41. Fong D, Kwok C, White K. Psychometric properties of the Chinese Breast Cancer Screening Beliefs Questionnaire. Eur J Oncol Nurs. 2012;165:505-11.

42. Hair J, Black W, Babin B, Anderson R, Tatham R. Multivariate data analysis. 6th ed. New Jersey: Prentice-Hall International; 2006.

43. Lee H, Kim J, Han H. Do cultural factors predict mammography behaviours among Korean immigrants in the USA? J Adv Nurs. 2009;6512:2574-84.
44. Mamdouh HM, El-Mansy H, Kharboush IF, Ismail HM, Tawfik MM, El-Baky MA et al. Barriers to breast cancer screening among a sample of Egyptian females. J Fam Community Med. 2015;212:119-24.

45. Kim J, Lee SK, Lee J, Choi MY, Jung SP, Kim MK, et al. Breast cancer screening knowledge and perceived health beliefs among immigrant women in Korea. J Breast Cancer. 2014;173:279-86.

46. Tripathi N, Kadam YR, Dhobale RV, Gore AD. Barriers for early detection of cancer amongst Indian rural women. South Asian J Cancer. 2014;32:122-7.

\section{Submit your next manuscript to BioMed Central and we will help you at every step:}

- We accept pre-submission inquiries

- Our selector tool helps you to find the most relevant journal

- We provide round the clock customer support

- Convenient online submission

- Thorough peer review

- Inclusion in PubMed and all major indexing services

- Maximum visibility for your research

Submit your manuscript at www.biomedcentral.com/submit
Biomed Central 